\title{
High Density Solvent Based Dispersive Liquid-Liquid Microextraction Technique for Simultaneous and Selective Extraction of Multiclass Pesticide Residues in Water and Sugarcane Juice Samples
}

\author{
Teshome Tolcha, Negussie Megersa* \\ Department of Chemistry, Addis Ababa University, Addis Ababa, Ethiopia \\ Email: *megersane@yahoo.com, *negussie.megersa@aau.edu.et
}

How to cite this paper: Tolcha, T. and Megersa, N. (2018) High Density Solvent Based Dispersive Liquid-Liquid Microextraction Technique for Simultaneous and Selective Extraction of Multiclass Pesticide Residues in Water and Sugarcane Juice Samples. American Journal of Analytical Chemistry, 9, 224-244.

https://doi.org/10.4236/ajac.2018.94018

Received: February 23, 2018

Accepted: April 21, 2018

Published: April 24, 2018

Copyright $(9) 2018$ by authors and Scientific Research Publishing Inc. This work is licensed under the Creative Commons Attribution International License (CC BY 4.0).

http://creativecommons.org/licenses/by/4.0/

\begin{abstract}
In this study, a miniaturized analytical technique based on high density solvent based dispersive liquid-liquid microextraction (HD-DLLME) was developed for extraction of trace residues of multiclass pesticides including three $s$-triazine herbicides, two organophosphate insecticides and two organochlorine fungicides from environmental water and sugarcane juice samples. The analytical method was validated and found to offer good linearity: $\mathrm{R}^{2} \geq 0.991$; repeatability varied from $0.73 \%-5.28 \%$; reproducibility varied from $1.14 \%$ $8.74 \%$ and limit of detection ranged from 0.005 to $0.02 \mu \mathrm{g} / \mathrm{L}$. Moreover, accuracy of the optimized method was evaluated and the recovery was varied from $80.39 \%-114.05 \%$. Analytical applications of this method to environmental waters and sugarcane juice samples indicate the presence of trace residues of ametryn in the lake water and sugarcane juice samples. Atrazine and ametryn were also detected in irrigation water.
\end{abstract}

Keywords

HD-DLLME, GC-MS, Sample Preparation, Multiclass Pesticides, Sugarcane Juice

\section{Introduction}

During the recent years, potential health risks originated from pesticides and other organic pollutant residues in food and environment have become the major threats attracting the attentions of legislative authorities [1] [2]. Some of the 
chemical classes of pesticides that are widely used for controlling or killing of plant diseases and weeds include the $s$-triazine herbicides [3] [4], organophosphate insecticides [5] [6] [7] and organochlorine fungicides [8] [9]. Despite their usefulness in agriculture and health sectors, their extensive uses resulted in contamination of the atmosphere, environmental waters, soils and agricultural products [10] [11] [12]. However, environmental monitoring of pesticides in developing countries is often constrained by the absence or limited infrastructures for most localities and/or scarcity of equipped laboratories for analysis of contamination levels [13] [14]. Thus, efforts for investigating analytical methods that are requiring simpler equipments must be considered for enabling fairly reliable and accurate analysis of the pollutant residues to safeguard human health risks and support the compliance and enforcement of the laws and regulations pertaining to the food safety.

Due to their occurrence at trace levels and the complexity of environmental samples, analysis of pesticide residues requires selective and efficient sample preparation methods that enable simultaneous extraction and preconcentration, prior to their instrumental determination [15] [16] [17] [18]. Besides, when multiclass pesticide residues are coexisting in different matrices, their simultaneous isolation and enrichment into non-polar organic solvents is a challenging experimental task mainly due to their different physicochemical properties and composition. Traditionally, extraction of pesticide residues at trace levels relies on the use of liquid-liquid extraction (LLE) [18] [19] and solid-phase extraction (SPE) [15]. However, LLE has drawbacks including consumption of expensive organic solvents, often tiresomeness, formation of emulsions, difficulties of automation and on-line connection to analytical instruments, etc. [18]. On the other hand, the use of SPE is also associated with the problem of choice of appropriate sorbent, optimization of column conditioning and use of organic solvents for elution [15].

Recent research interests have received emphasis towards development of efficient, economical, miniaturized and automated extraction techniques that could greatly reduce consumption of toxic organic solvents [16] [17]. To this end, solid phase microextraction (SPME), single drop microextraction (SDME) and hollow-fiber liquid-phase microextraction (HF-LPME) techniques have been developed and widely used as methods of choice for critically minimizing or avoiding uses of organic solvents in sample preparation procedures [9]. However, SPME is expensive; its fiber is fragile; it has limited lifetime and requires long time for sorbent conditioning [11]. On the other hand, drop instability in SDME [9] and also poor reproducibility in HF-LPME are the major limitations of these methods [11].

To overcome these limitations, Assadi and coworkers developed dispersive liquid-liquid microextraction (DLLME) technique [20]. It is a modified version of solvent extraction technique in which acceptor to donor phase ratio is greatly reduced compared to other methods used for similar purposes [21] [22] [23]. 
The principle of trace enrichment in DLLME is based on a ternary component solvent system, in which extraction and disperser solvents are rapidly introduced into the aqueous sample to form a cloudy solution. Extraction equilibrium is quickly achieved, mainly because of extensive surface contacts between the droplets of the extraction solvent and aqueous sample solution [21] [22]. Furthermore, as microextraction technique, DLLME has advantages of simplicity of operation, rapidity, low cost, high recovery, use of cheap and commonly available laboratory devices and environmental benignity [24].

Since its introduction, the DLLME technique has been used for extraction of trace organic and inorganic pollutants such as polycyclic aromatic hydrocarbons, aromatic amines, metals, antioxidants and some class of pesticides; mainly from water [25] and to lesser extents in foods [26], especially in juices [27] and vegetables [28]. However, there are very few literature reports on application of the technique for determination of pesticides in waters [29] and none on the use of high density solvent based dispersive liquid-liquid microextraction (HD-DLLME), for simultaneous extraction of multiclass pesticide residues from water, of different sources, and sugarcane juice samples. Thus, the major purpose of the current study is to develop a new analytical method based on HD-DLLME for simultaneous isolation and enrichment of trace quantities of seven multiclass pesticides: three $s$-triazine herbicides, two organophosphate insecticides and two organochlorine fungicides; from contaminated water samples collected from Hawassa Lake and Wonji Shoa sugarcane irrigation, and sugarcane juice samples in Ethiopia.

\section{Experimental}

\subsection{Chemicals and Reagents}

All the solvents used in this study were of HPLC grade, and the chemicals and reagents were also of analytical grade. The disperser and extraction solvents were obtained from different sources: methanol was purchased from Acros organics (New Jersey, USA); acetone from Scharlau (Barcelona, Spain) and acetonitrile from Sigma-Aldrich Chemie GmbH (Buchs, Switzerland), carbon tetrachloride from BDH Chemicals Ltd. (Poole, England); tetrachloroethylene from May and Baker Ltd. (Dagenham, England) and chloroform from Sigma Aldrich (Seelze, Germany). Extra pure sodium chloride was purchased from Oxford laboratory (Mumbai, India) and used to study the effect of ionic strength. Sodium hydroxide pellet was from BDH Laboratory Supplies (Poole, England) and hydrochloric acid from Sigma-Aldrich Chemie GmbH (Steinheim, Germany) and used to adjust the sample $\mathrm{pH}$. Ultrapure water used as reagent water during method development and application was obtained by purifying with double distiller, A8000 Aquatron water Still (Bibby Scientific, Staffordshire, UK) and deionizer (EASYPure LF, Dubuque).

All the standards of pesticide compounds; viz., atrazine, diazinon, chlorothalonil, ametryn, malathion, chlorpyrifos and dimethametryn (Figure 1) are of 
<smiles>CCNc1nc(Cl)nc(NC(C)C)n1</smiles>

Atrazine

(LogP: -0.97 , pKa: 1.7)<smiles>CCOP(=S)(OCC)Oc1cc(C)nc(C(C)C)n1</smiles>

Diazinon

(Log P: 3.69, pKa: 2.6)<smiles>CCNc1nc(NC(C)C)nc(NC(C)C)n1</smiles>

Ametryn

(Log P: na, pKa: 4.1)<smiles>CCOC(=O)CC(SP(=S)(OC)OC)C(=O)OCC</smiles>

Malathion

(Log P: 2.75, pKa: na)<smiles>N#Cc1c(Cl)c(Cl)c(Cl)c(C#N)c1Cl</smiles>

Chlorothalonil

(Log P: 2.94, pKa: na)<smiles>CCOP(=S)(OCC)Oc1nc(Cl)c(Cl)cc1Cl</smiles>

Chlorpyrifos

(Log P: 4.0, pKa: na)<smiles>CCNc1nc(NC(C)C(C)C)nc(SC)n1</smiles>

Dimethametryn

(Log P: 3.9, pKa: 4.0)

Figure 1. Chemical structures, common names, $\log \mathrm{P}$ and $\mathrm{pK}_{\mathrm{a}}$ of the pesticides considered in this study [30] [31].

analytical reagent grade and were purchased from Dr. Ehrenstorfer $\mathrm{GmbH}$ (Augsburg, Germany). Stock standard solution of $100 \mathrm{mg} / \mathrm{L}$ of the target analytes was prepared in methanol. Working solutions of $1 \mathrm{mg} / \mathrm{L}$ were prepared once in a week by diluting the standard stock solution in methanol. A series of solutions for calibration were prepared in reagent water, at five concentration levels, from the working solution. Reagent water was spiked at $5 \mu \mathrm{g} / \mathrm{L}$ concentration level once in a day using a standard solution containing the mixture of the target analytes for parameter optimization. Similarly, 2.5 and $5 \mu \mathrm{g} / \mathrm{L}$ mixture of the pesticide compounds was also prepared, in the same manner as above, for determination of the percent recovery (\%RR). All solutions were stored in the dark at $4^{\circ} \mathrm{C}$ until the time of analysis and when not in use.

\subsection{GC-MS Analysis}

Agilent Technologies, 7820A gas chromatography (GC) equipped with Agilent 
Technologies, 5977E inert mass spectrometry (MS) detector was used to analyze the pesticide compounds. GC separations were carried out on $\mathrm{Hp}-5 \mathrm{~ms}$ ultra inert capillary column $(25 \mathrm{~m} \times 250 \mu \mathrm{m}$ and $0.25 \mu \mathrm{m}$ i.d). Helium gas (99.999\%) was used as carrier gas at a flow rate of $1 \mathrm{~mL} / \mathrm{min}$ and the analytical results obtained were interpreted using mass hunter Chem-Station. The oven temperature program employed for separation were as follows: $130^{\circ} \mathrm{C}$ for $0 \mathrm{~min}$; increased at $25^{\circ} \mathrm{C} / \mathrm{min}$ to $185^{\circ} \mathrm{C}$ held for $1 \mathrm{~min}$; then increased at $9^{\circ} \mathrm{C} / \mathrm{min}$ to $200^{\circ} \mathrm{C}$ for $1 \mathrm{~min}$ and $10^{\circ} \mathrm{C} / \mathrm{min}$ to $290^{\circ} \mathrm{C}$ held for $1 \mathrm{~min}$. The GC oven and injection port temperature were maintained at $290^{\circ} \mathrm{C}$ and $250^{\circ} \mathrm{C}$, respectively.

All injections were made in splitless mode. The mass detector was used in the full scan mode and scanned over the range $\mathrm{m} / \mathrm{z} 50$ - 550 to confirm the retention times of the analytes. Selective ion monitoring (SIM) mode was used for determination of all the analytes. Confirmation of the identity of pesticides was made by selecting the most abundant characteristic ions of each pesticide and two characteristic fragment ions. The $\mathrm{m} / \mathrm{z}$ selected for SIM mode detection was as follows: atrazine (215.1, 200.1 and 173.1), diazinon (152.1, 137.1 and 124.1), chlorothalonil (267.9, 265.9 and 263.9), ametryn (228.1, 227.1 and 226.1), malathion (178.1, 174.1 and 158.1), chlorpyrifos (198.9, 196.9 and 179.1) and dimethametryn $(213.1,212.1$ and 196.1).

\subsection{Sampling Sites and Sample Collection}

Two different water samples were collected from Hawassa Lake; located at $7^{\circ} 01^{\prime} 52.67^{\prime \prime} \mathrm{N}$ latitude and $38^{\circ} 25^{\prime} 18.79^{\prime \prime}$ E longitude with elevation of $1685 \mathrm{~m}$ above sea level and Wonji Shoa sugarcane irrigation; at latitude of $8^{\circ} 27^{\prime} 15.35^{\prime \prime} \mathrm{N}$ and longitude of $39^{\circ} 13^{\prime} 49.33^{\prime \prime E}$ longitude with elevation of $1552 \mathrm{~m}$ above sea level. Similarly, sugarcane juice sample was collected from Wonji Shoa sugar factory, all in Ethiopia. All the samples collected for this study were stored in brown glass bottles and transported to the analytical laboratory of the Department of Chemistry, Addis Ababa University. They were then kept in a refrigerator, at $4^{\circ} \mathrm{C}$ in the dark, for a maximum of $24 \mathrm{~h}$ [32]. The samples were then filtered through cellulose acetate filter papers $(0.45 \mu \mathrm{m}$, MicroScience and $110 \mathrm{~mm}$ Smith F1/KA4, Germany) for further analysis. A $5 \mathrm{~mL}$ sugarcane juice sample was diluted to $15 \mathrm{~mL}$ with reagent water. Specifically, the sugarcane juice sample was centrifuged for $15 \mathrm{~min}$ at $3800 \mathrm{rpm}$ (Scientific Ltd, K240, UK). After centrifugation, $5 \mathrm{~mL}$ of the supernatant was filtered and subjected to the DLLME procedure. A modified $5 \mathrm{~mL}$ micropipette tip was used as extraction vessel. The micropipette tip was burned using match flame to close the tip.

\subsection{HD-DLLME Procedure}

Initially, $5 \mathrm{~mL}$ of the pretreated water and sugarcane samples were adjusted to $\mathrm{pH} 7$, separately in a beaker. Each resulting solution was then spiked into appropriate quantity of standard solution containing the mixture of the analytes under study. Afterwards, a mixture containing $40 \mu \mathrm{L}$ chloroform and $0.4 \mathrm{~mL}$ 
methanol was injected rapidly into the sample solution, in the modified micropipette tip. Then, the contents (sample solution, extraction solvent and disperser solvent) in the tip ended up with emulsion formation. The cloudy solution was left to stand for $3 \mathrm{~min}$ and then the content was centrifuged at $4000 \mathrm{rpm}$ (Centrifuge model 800 , China) for $3 \mathrm{~min}$, for allowing phase separation. This was followed by collection of the sedimented phase, using $100 \mu \mathrm{L}$ microsyringe (microliter ${ }^{\circledR} \# 710$ ) as indicated in Figure 2. Finally, $1 \mu \mathrm{L}$ of each extract was injected into a GC-MS system for analysis.

\section{Results and Discussion}

\subsection{Optimization of HD-DLLME Parameters}

In order to attain a reliable or applicable extraction procedure utilizing HD-DLLME, investigation of the effects of various experimental parameters and determining the optimum conditions must always be considered. In the analytical method developed, in this study, all experimental variables affecting the performances of the technique including the effect of the type and volume of extraction solvent as well as disperser solvent, the shaking speed and time, extraction time, $\mathrm{pH}$ of the sample solution and variation in quantities of the salt added have been investigated and optimized. For analyses of the analytes, peak areas
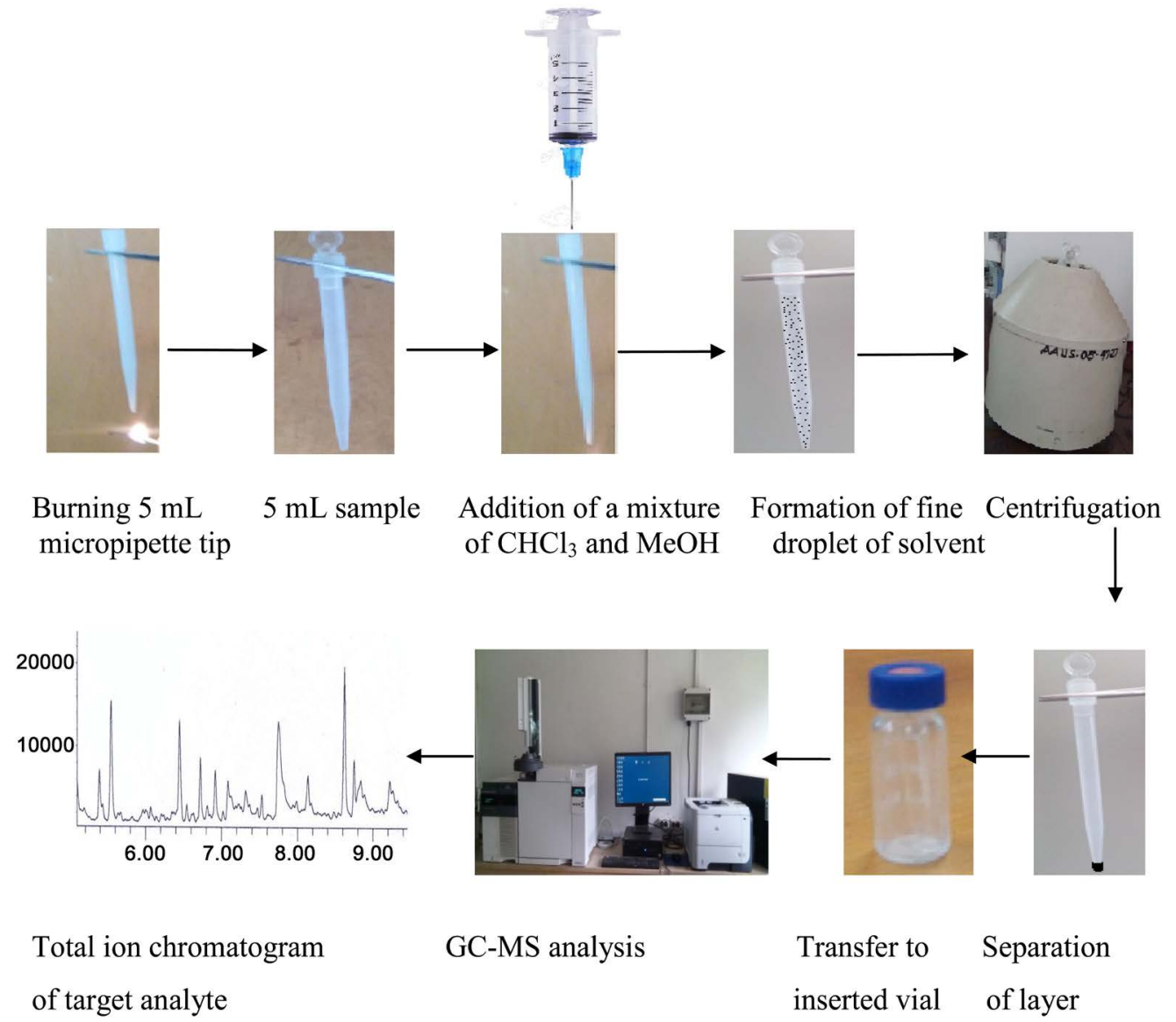

Figure 2. Experimental set-up of the proposed HD-DLLME extraction procedure. 
were used to evaluate the extraction efficiency and establish the optimum extraction conditions.

\subsubsection{Selection of the Extraction Solvent}

Selection of appropriate extraction solvent is the primary step in the optimization procedure. Generally, in the HD-DLLME techniques, extraction solvent should meet the following requirements: it should (a) have high density than water, (b) be insoluble in water, (c) have high extraction capability for the target analytes and (d) have good chromatographic behavior [18] [27] [33].

In this study, analytical performances of chloroform, tetrachloroethylene and carbon tetrachloride, as extraction solvent, were evaluated. Based on the experimental results obtained, Figure 3, the highest responses, as peak area, were observed when chloroform was used as extraction solvent. Thus, chloroform was chosen as extraction solvent for further studies.

\subsubsection{Effect of the Volume of Extraction Solvent}

In order to investigate the effect of extraction solvent volume on the extraction efficiency, volume of chloroform was varied from 40 to $80 \mu \mathrm{L}$, in a constant volume of methanol $(0.5 \mathrm{~mL})$ for quantitative extraction of multiclass pesticides by HD-DLLME. It was noticed that, below $40 \mu \mathrm{L}$ of the solvent volume, formation of the sedimented phase was not satisfactory and thus collection of the sedimented phase was found to be difficult. On the other hand, at higher volumes of the extraction solvent the ratio between the disperser solvent and that of extraction solvent exhibited decreasing tendencies which could probably resulted in

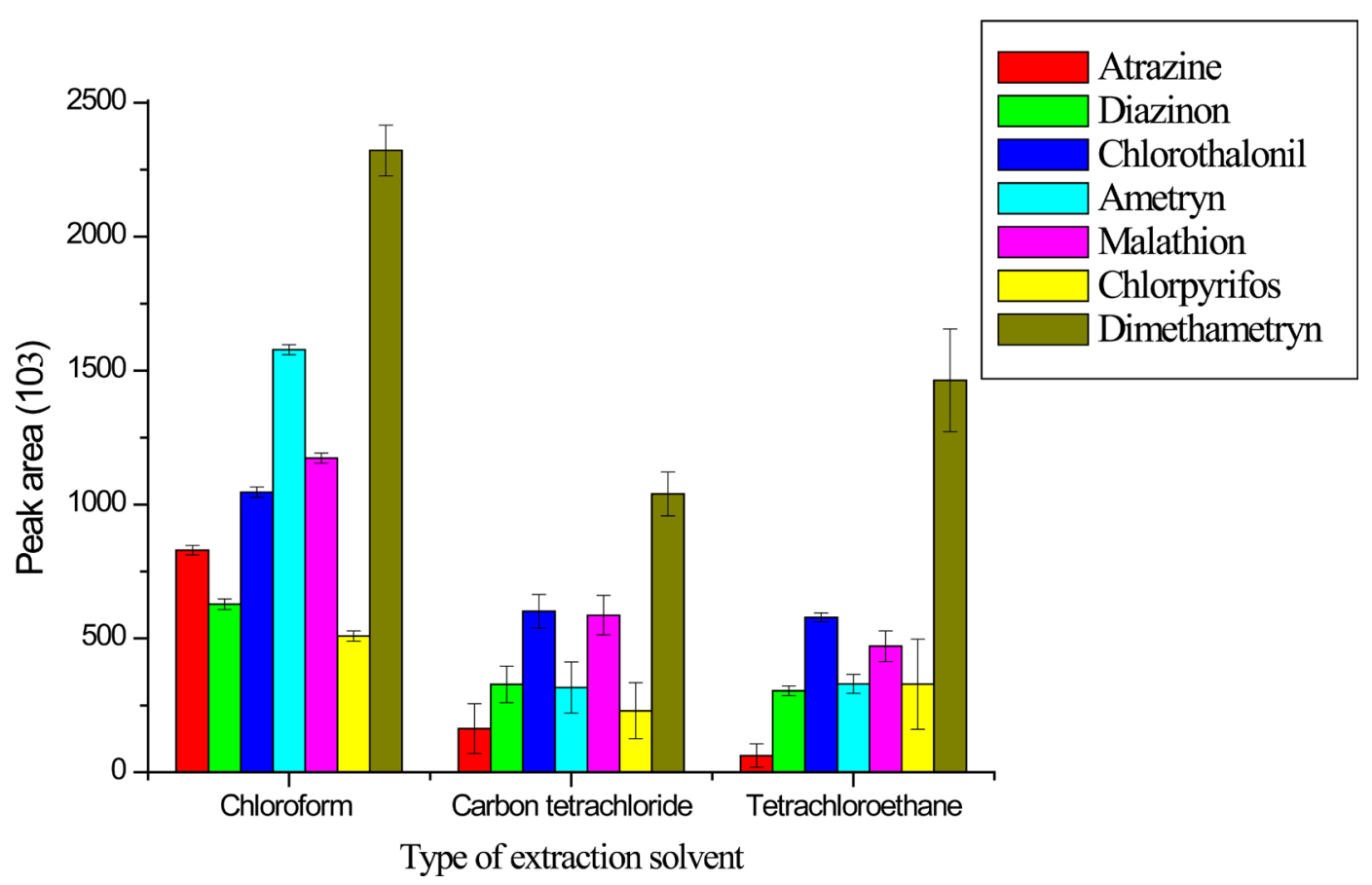

Figure 3. Effect of the type of extraction solvent on the HD-DLLME efficiency. Extraction conditions: sample size, $5 \mathrm{~mL}$; spiked concentration, $5 \mu \mathrm{g} / \mathrm{L}$; extraction solvent volume, $50 \mu \mathrm{L}$; disperser solvent, $0.5 \mathrm{~mL}$ methanol; extraction time, $1 \mathrm{~min}$; centrifugation speed $3500 \mathrm{rpm}$ for $3 \mathrm{~min}, n=3$. 
reduced quantity of the droplets formed and thereby decreased extraction efficiency [16]. Therefore, $40 \mu \mathrm{L}$ chloroform, which resulted in the highest signals, was chosen as the optimum volume of the extraction solvent.

\subsubsection{Selection of the Disperser Solvent}

An ideal disperser solvent, used in DLLME, must have the capacity to make finer droplets of the extraction solvent and disperse extraction solvent in the sample bulk [1] [20]. Furthermore, the disperser solvent should be miscible both in the organic and aqueous phases in order to form a distinct cloudy solution [28] [34]. The type of disperser solvent can also influence viscosity of the organic phase and therefore affect the stability of the cloudy solution [35] [36]. In the HD-DLLME technique investigated, performances of three extraction solvents including acetone, acetonitrile and methanol were evaluated. The analytical results obtained, as peak areas, were found to be the highest, when methanol was used as disperser solvent. It was also observed that methanol fulfills the major characteristics that the disperser solvent possesses than the other two solvents [36]. As a result, methanol was selected as disperser solvent and utilized for further experiments.

\subsubsection{Effect of Volume of the Disperser Solvent}

The influence of the disperser solvent volume on extraction efficiency of the HD-DLLME technique was studied over the range of $0.3-0.6 \mathrm{~mL}$ of methanol. As shown in Figure 4, it was noted that below $0.3 \mathrm{~mL}$ of methanol layer formation was not observed. However, the peak areas showed increasing tendency

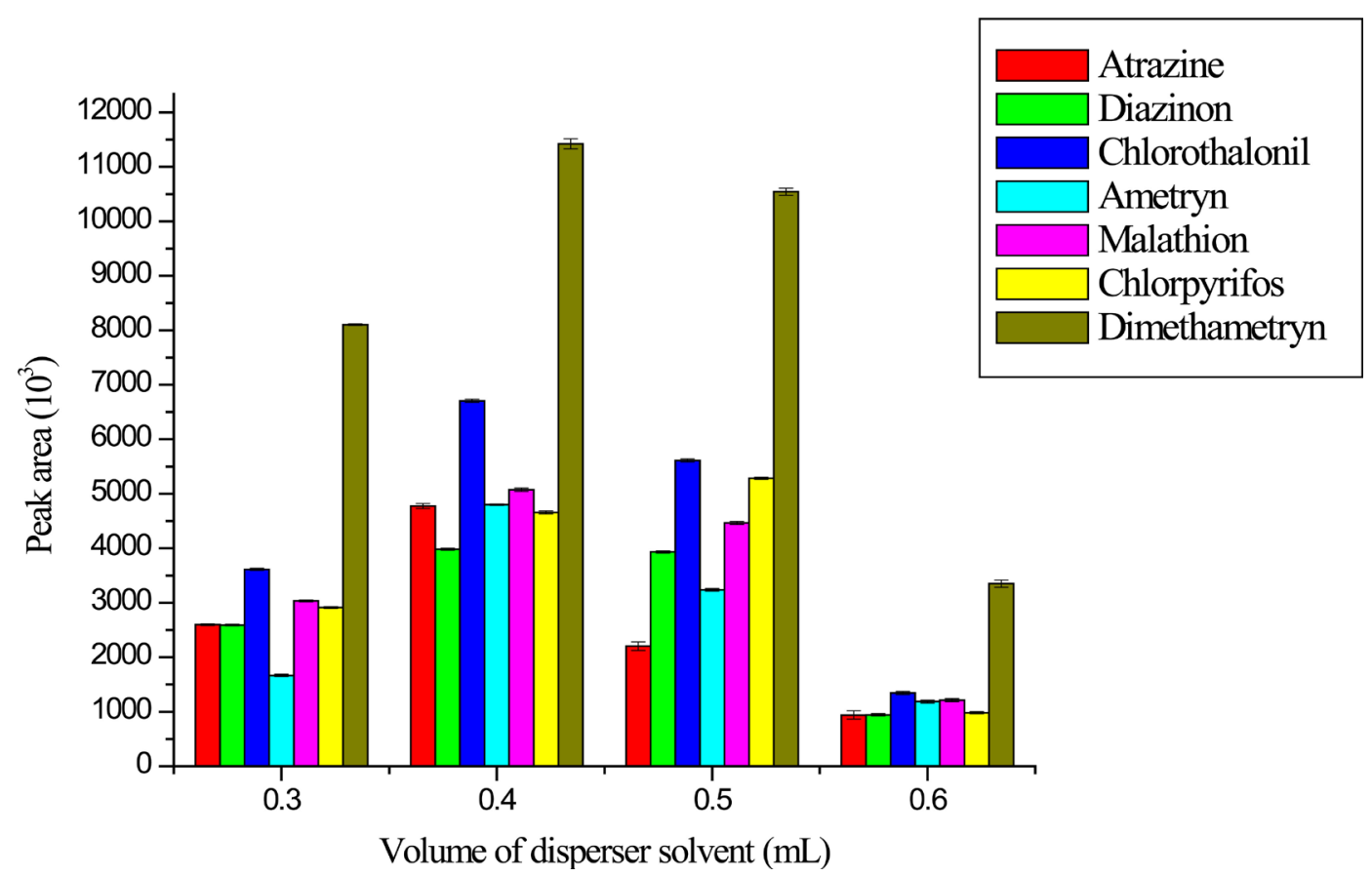

Figure 4. Effect of the volume of disperser solvent on the HD-DLLME efficiency. Extraction conditions: sample size, $5 \mathrm{~mL}$; spiked concentration, $5 \mu \mathrm{g} / \mathrm{L}$; extraction solvent, $40 \mu \mathrm{L}$ chloroform; disperser solvent, methanol; extraction time, $1 \mathrm{~min}$; centrifugation speed $3500 \mathrm{rpm}$ for $3 \mathrm{~min}, n=3$. 
when the volume of methanol was increased, from 0.3 to $0.4 \mathrm{~mL}$. This may be attributed to the fact that smaller volumes, less than $0.4 \mathrm{~mL}$, can't sufficiently disperse the extraction solvent. On the other hand, further increase in the disperser solvent volume, beyond $0.4 \mathrm{~mL}$, decreased the aqueous phase polarity, and thereby causing increased solubility of the target analytes in the aqueous phase [37]. Thus, disperser solvent volume of $0.4 \mathrm{~mL}$ was chosen as the optimum volume and used in the subsequent experiments.

\subsubsection{Effect of the Extraction Time}

Mass transfer is a time dependent process and is also one of the salient factors in most of the extraction procedures, particularly in miniaturized extractions such as SPME and LPME [1] [38]. In the DLLME, equilibrium is achieved so quickly, which may mainly be attributed to the instant transition of the analytes, from aqueous phase to the extraction solvent. This is most probably facilitated by the presence of large surface areas of contact between the extraction solvent and the aqueous phase, during formation of cloudy solution [18] [23]. In DLLME, extraction time is specifically defined as the time interval between injecting the mixture of disperser solvent and extraction solvent into the sample solution and starting centrifugation [39]. Accordingly, in the current study the effect of extraction time on the extraction technique was investigated over the range of 1 - 5 min. It was noted that the responses showed increasing tendency at the beginning, i.e., $1 \mathrm{~min}$, than those of $2 \mathrm{~min}$, although for most of the target analytes, analytical results obtained for $3 \mathrm{~min}$ extraction were found to be highest. This may be attributed to the very fast mass transfer taking place initially but before establishment of the equilibrium state, which was achieved later, around $3 \mathrm{~min}$ (Figure 5). Therefore, extraction time of $3 \mathrm{~min}$ was found to be the optimum time and used throughout this study.

\subsubsection{Effect of the Centrifugation Speed}

Centrifugation speed is one of the most important parameters in the sample preparation steps and also plays a key role in separation of the phases and thus resulting in a clear solution in HD-DLLME techniques [38]. In order to obtain the highest signal, the speed was varied from 2500 to $4000 \mathrm{rpm}$. The corresponding experimental results, revealed that the peak areas were increasing with the centrifugation speed (Figure 6) up to $4000 \mathrm{rpm}$. Extractions, at higher speeds than $4000 \mathrm{rpm}$, were not performed because of the instrumental limitation, i.e., $4000 \mathrm{rpm}$ is the maximum speed, which was used as the optimum centrifugation speed throughout the study.

\subsubsection{Effect of the Centrifugation Time}

In DLLME procedures, optimizing the time required for phase separation is also important analytical step, in order to obtain a clear extract [39]. In order to establish the optimum conditions, centrifugation time was varied from 1 - 5 min, at constant speed of $4000 \mathrm{rpm}$. Based on the peak areas representing the target analytes, the highest results were obtained at the centrifugation time of $3 \mathrm{~min}$. 


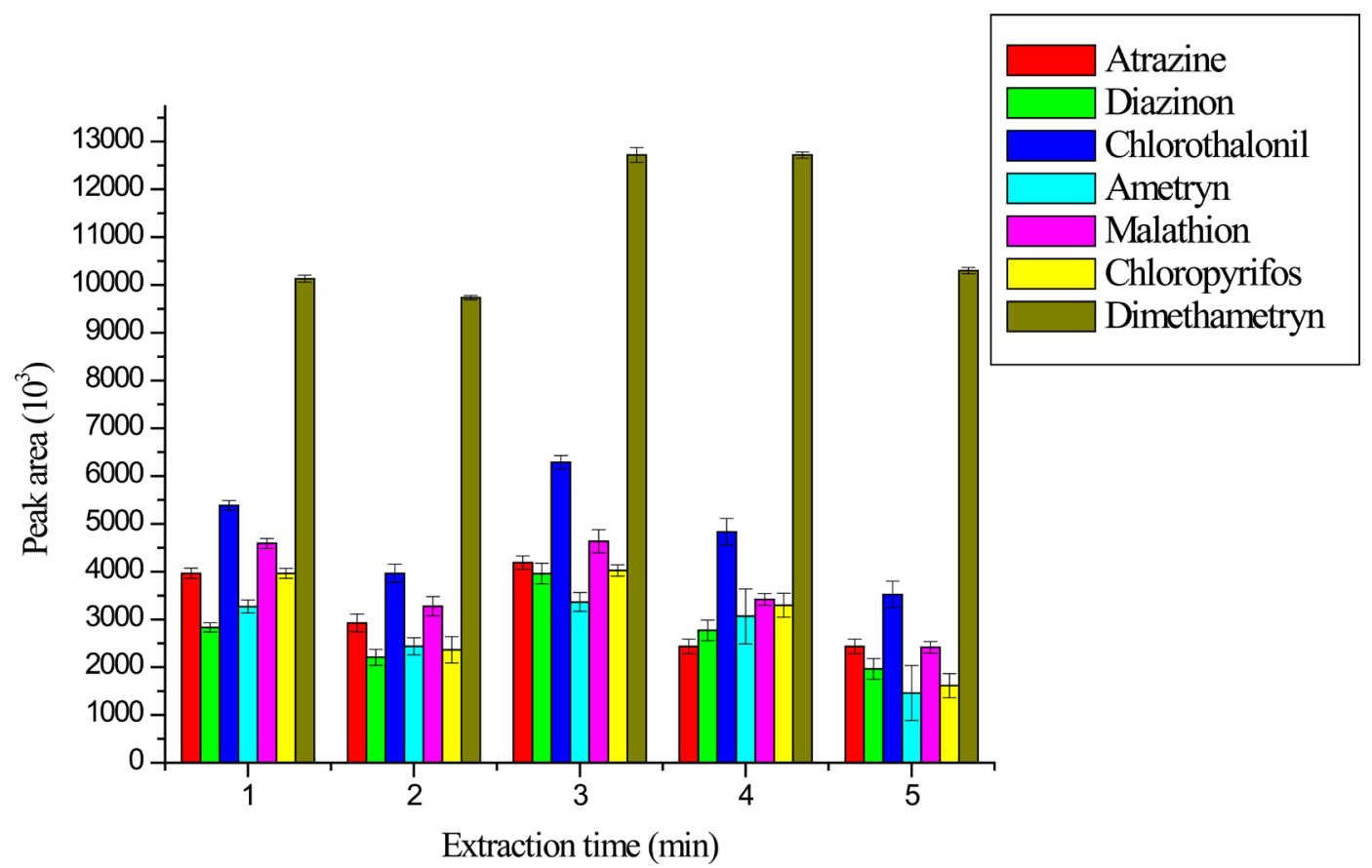

Figure 5. Effect of the extraction time on the HD-DLLME efficiency. Extraction conditions: sample size, 5 $\mathrm{mL}$; spiked concentration, $5 \mu \mathrm{g} / \mathrm{L}$; extraction solvent, $40 \mu \mathrm{L}$ chloroform; disperser solvent, $0.4 \mathrm{~mL}$ methanol; centrifugation speed, $3500 \mathrm{rpm}$ for $3 \mathrm{~min}, n=3$.

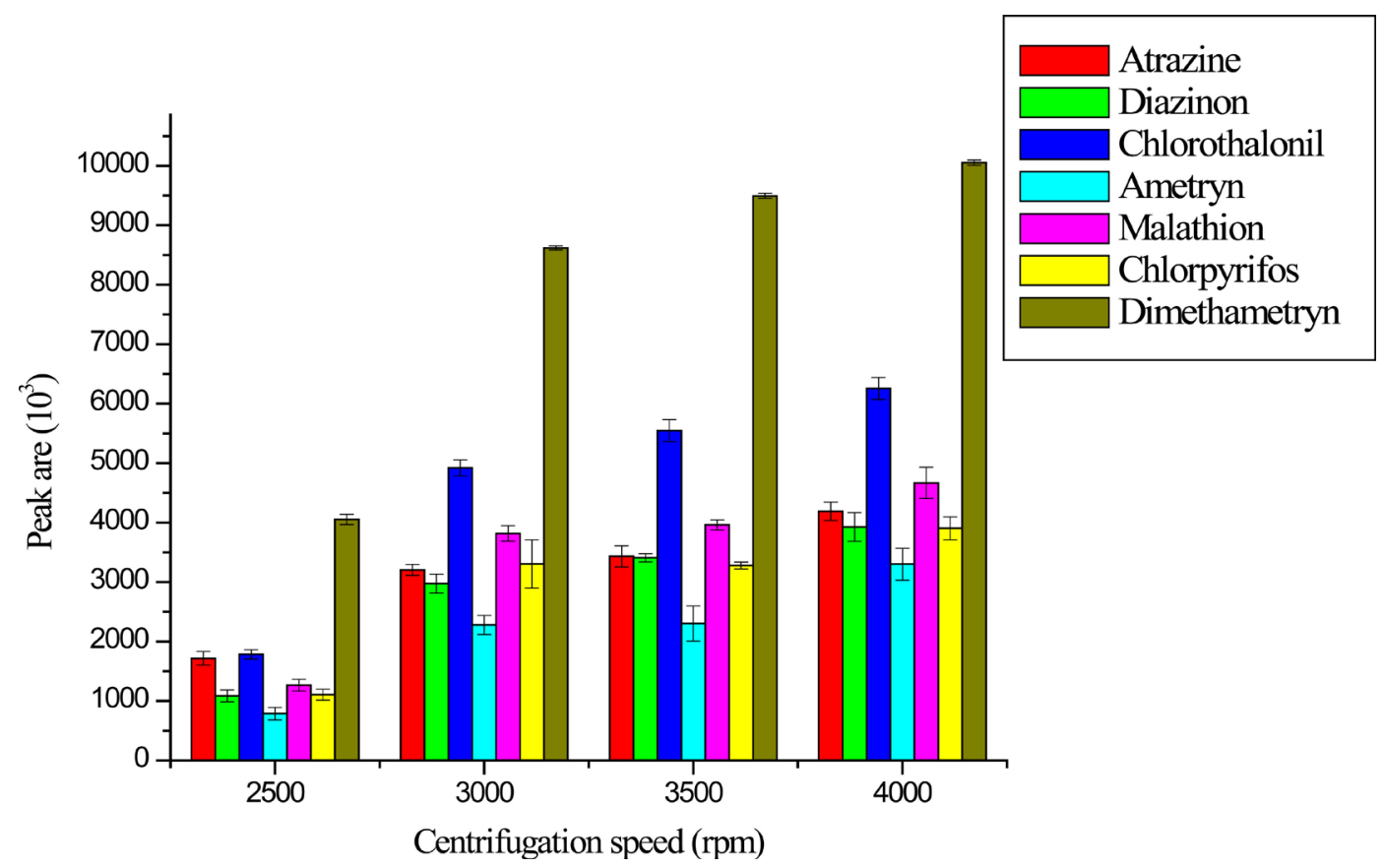

Figure 6. Effect of the centrifugation speed on the HD-DLLME efficiency. Extraction conditions: sample size, $5 \mathrm{~mL}$; spiked concentration, $5 \mu \mathrm{g} / \mathrm{L}$; extraction solvent, $40 \mu \mathrm{L}$ chloroform; disperser solvent, $0.4 \mathrm{~mL}$ methanol; centrifugation time, $3 \mathrm{~min}, n=3$.

Similar observations to that of the extraction time were also noted here for initial time of centrifugation for establishing equilibrium. Beyond $3 \mathrm{~min}$, the peak areas were found to decrease gradually and thus centrifugation time of 3 min was 
chosen as optimum and used in the subsequent analysis.

\subsubsection{Effect of the Sample Solution $\mathrm{pH}$}

The sample solution $\mathrm{pH}$ has also significant role on the extraction efficiency of the multiclass pesticides using the HD-DLLME procedure [40] [41]. In order to evaluate the effect of this parameter, series of experiments were carried out by varying $\mathrm{pH}$ of the original aqueous solution from 5 to 9 . The experimental results obtained revealed that $\mathrm{pH} 7$ was the optimum $\mathrm{pH}$, Figure 7, which may be associated with enhanced stability of the target analytes in the weakly acidic and weakly alkaline environments, while they were easily degraded in strongly acidic and alkaline conditions [42] [43].

\subsubsection{Effect of the Salt Addition}

Generally, in LPME, addition of the salt to solution reduces solubility of the analytes in the aqueous sample solution and as a result enhances their partitioning into the organic phase [44]. In this study, effect of the amount of the salt was studied by adding varied quantities of $\mathrm{NaCl}(0,2.5,5$ and $7.5 \% \mathrm{w} / \mathrm{v})$ to the aqueous sample solutions. It was observed that addition of $\mathrm{NaCl}$ resulted in a reverse effect on extraction efficiency. This may be because salt addition decreased the peak areas of the analytes, since dissolution of sodium chloride in water may increase electrostatic interaction, which could most likely cause the extent of analytes transfer to the extraction phase to be reduced. In other words, presence of salt may also have the effect of decreasing solubility of chloroform in water, and this in turn may cause the volume of the sedimented phase to increase.

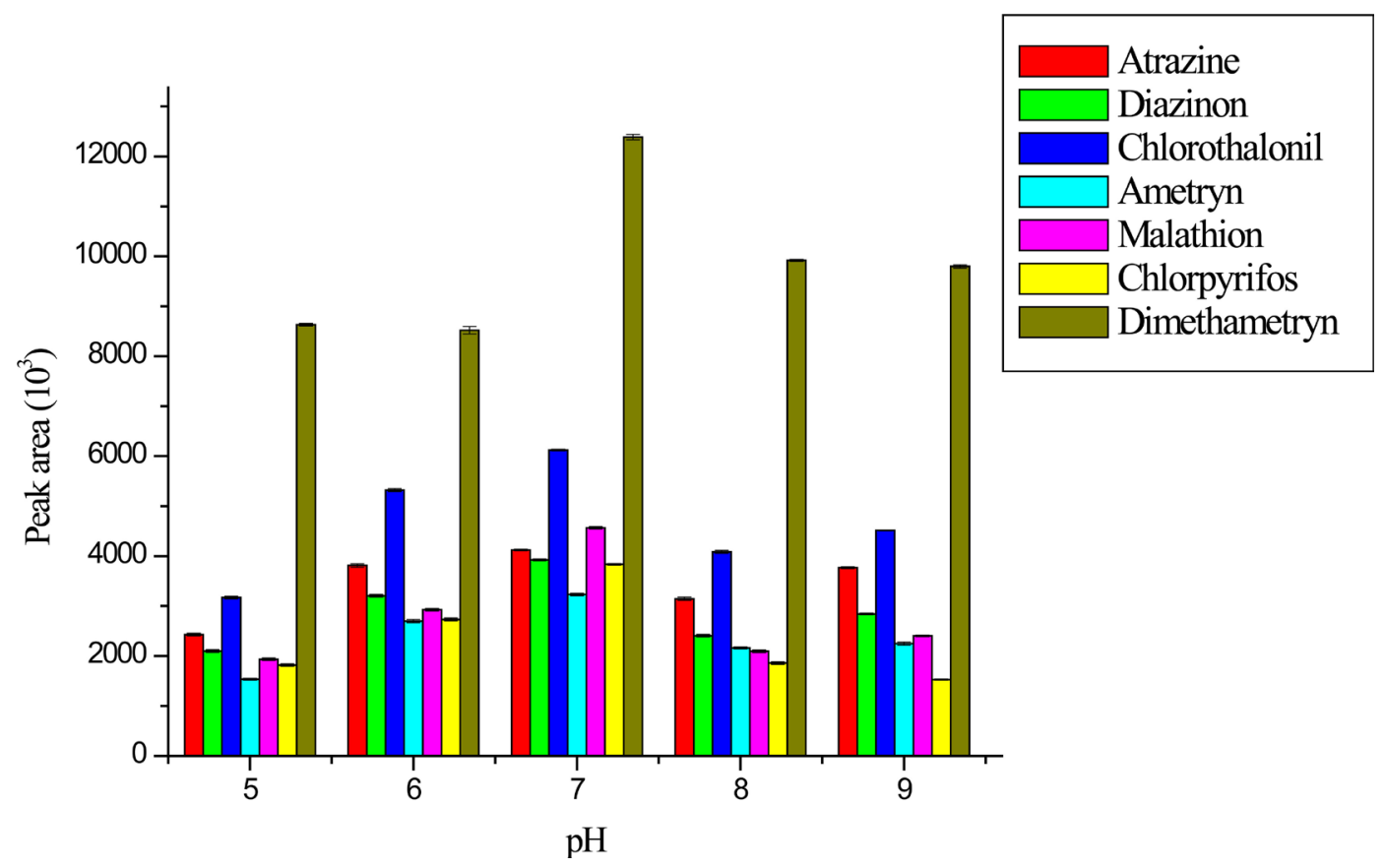

Figure 7. Effect of sample $\mathrm{pH}$ on the HD-DLLME efficiency. Extraction conditions: sample size, $5 \mathrm{~mL}$; spiked concentration, $5 \mu \mathrm{g} / \mathrm{L}$; extraction solvent, $40 \mu \mathrm{L}$ chloroform; disperser solvent, $0.4 \mathrm{~mL}$ methanol; extraction time, $3 \mathrm{~min}$; centrifugation speed $4000 \mathrm{rpm}$ for $3 \mathrm{~min}, n=3$. 
The ultimate effect could thus result in a decreased extraction efficiency [18] [28] [45]. Based on these observations, all the subsequent experiments were carried out without addition of salt solution.

\subsection{HD-DLLME Method Validation}

\subsubsection{Calibration Curves and Precision Study}

The proposed analytical method was validated by evaluating linearity, precisions and limits of detection (LOD). The linearity was established for five different concentration levels. Each concentration level was extracted in triplicate, following the optimized procedure and each extract was also injected in triplicate. Good linearities, ranging from 0.991 to 0.999 , were obtained for all the target analytes considered in this study. Repeatability (intra-day precision) was investigated by extracting the spiked reagent water at $5 \mu \mathrm{g} / \mathrm{L}$, prepared and injected in triplicate on the same day, under the same experimental conditions. Similarly, reproducibility (interday precision) of the method was evaluated using reagent water spiked at the same concentration levels, used for repeatability, during three consecutive days. As provided in Table 1, satisfactory precisions (RSD less than $10 \%$ ) were obtained in all cases [46]. The limit of detection (LODs) was determined as the lowest concentration yielding a signal to noise $(\mathrm{S} / \mathrm{N})$ ratio of 3 . The LODs of the analytes ranged from 0.005 to $0.02 \mu \mathrm{g} / \mathrm{L}$.

\subsubsection{Applications of the Method to Real Sample}

The proposed HD-DLLME-GC-MS technique was applied for selective and quantitative extraction and determination of seven pesticides in the water samples collected from Hawassa Lake and Wonji Shoa sugarcane irrigation water, and sugarcane juice samples from Wonji Shoa sugar factory, following the optimized analytical method. The matrix effect on the selective isolation and quantitative determination of the trace levels of the target analytes by the developed method was evaluated by percent relative recovery (\%RR). It is defined as the ratio of the peak area of the spiked real water extract to that of spiked reagent

Table 1. Performance characteristics of the proposed analytical method.

\begin{tabular}{ccccccc}
\hline Analyte & $\begin{array}{c}\text { Linear range } \\
(\mu \mathrm{g} / \mathrm{L})\end{array}$ & Regression equation & $\mathrm{R}^{2 \mathrm{a}}$ & $\begin{array}{c}\text { LOD } \\
(\mu \mathrm{g} / \mathrm{L})\end{array}$ & $\begin{array}{c}\mathrm{Rept}^{\mathrm{b}} \\
(\% \mathrm{RSD}, \\
\mathrm{n}=3)\end{array}$ & $\begin{array}{c}\mathrm{Repd}^{\mathrm{c}} \\
(\% \mathrm{RSD}, \\
\mathrm{n}=3)\end{array}$ \\
\hline Atrazine & $0.10-100$ & $\mathrm{y}=20141 \mathrm{x}+31927$ & 0.995 & 0.01 & 1.36 & 1.14 \\
Diazinon & $0.02-100$ & $\mathrm{y}=15334 \mathrm{x}+37096$ & 0.999 & 0.007 & 3.89 & 3.86 \\
Chlorothalonil & $0.10-100$ & $\mathrm{y}=28260 \mathrm{x}+86439$ & 0.997 & 0.02 & 0.73 & 4.85 \\
Ametryn & $0.02-100$ & $\mathrm{y}=12677 \mathrm{x}+16514$ & 0.991 & 0.008 & 0.82 & 8.74 \\
Malathion & $0.02-100$ & $\mathrm{y}=26235 \mathrm{x}+14121$ & 0.991 & 0.006 & 2.27 & 3.72 \\
Chlorpyrifos & $0.02-100$ & $\mathrm{y}=14695 \mathrm{x}+94087$ & 0.993 & 0.009 & 5.28 & 4.23 \\
Dimethametryn & $0.02-100$ & $\mathrm{y}=59031 \mathrm{x}+11517$ & 0.996 & 0.005 & 4.03 & 4.80 \\
\hline
\end{tabular}

${ }^{\mathrm{a}}$ Regression coefficient; ${ }^{\mathrm{b}}$ Repeatability; ${ }^{\mathrm{c}}$ Reproducibility. 
water extract spiked at the same level [29]. To study the matrix effect, two spiking levels $(2.5$ and $5 \mu \mathrm{g} / \mathrm{L}$ ) were considered and the resulting\% RR were found to vary from $80.4 \%$ to $114.0 \%$ with RSD varying from $0.27 \%-10.7 \%$ (Table 2 ); which were found to vary within the acceptable range [46]. These results demonstrate that the matrices had insignificant effect on the novel HD-DLLME technique developed in this study.

The presence of the seven pesticide residues in the three samples were investigated and only ametryn was detected in the water sample from Lake Hawassa at $1.45 \mu \mathrm{g} / \mathrm{L}$ level. Similarly, atrazine and ametryn were detected in the water sample collected from Wonji Shoa sugarcane irrigation at concentration levels 4.12 and $4.80 \mu \mathrm{g} / \mathrm{L}$, respectively. Ametryn was also detected in the sample of sugarcane juice at the concentration level of $7.06 \mu \mathrm{g} / \mathrm{L}$. The United States Environmental Protection Agency (US EPA) set the maximum allowable level of

Table 2. Recovery values of the proposed method in environmental water and sugarcane juice samples.

\begin{tabular}{|c|c|c|c|c|}
\hline \multirow{2}{*}{ Analyte } & \multirow{2}{*}{$\begin{array}{c}\text { Spiking } \\
\text { level } \\
(\mu \mathrm{g} / \mathrm{L})\end{array}$} & $\begin{array}{l}\text { Lake Hawassa } \\
\text { water samples }\end{array}$ & $\begin{array}{l}\text { Wonji Shoa sugarcane } \\
\text { irrigation water samples }\end{array}$ & $\begin{array}{l}\text { Sugarcane juice } \\
\text { samples }\end{array}$ \\
\hline & & $\begin{array}{c}\% \mathrm{RR} \\
(\% \mathrm{RSD}, \mathrm{n}=3)\end{array}$ & $\begin{array}{c}\% \mathrm{RR} \\
(\% \mathrm{RSD}, \mathrm{n}=3)\end{array}$ & $\begin{array}{c}\% \mathrm{RR} \\
(\% \mathrm{RSD}, \mathrm{n}=3)\end{array}$ \\
\hline \multirow{3}{*}{ Atrazine } & 0 & nd & $\mathrm{d}(4.12 \mu \mathrm{g} / \mathrm{L})$ & nd \\
\hline & 0.25 & 90.34 (7.49) & $114.05(5.22)$ & $93.75(5.85)$ \\
\hline & 5 & $108.60(3.45)$ & $104.03(2.45)$ & $110.48(4.83)$ \\
\hline \multirow{3}{*}{ Diazinon } & 0 & nd & nd & nd \\
\hline & 0.25 & $110.52(1.00)$ & $96.38(0.27)$ & $81.40(5.18)$ \\
\hline & 5 & $109.08(5.69)$ & $81.53(5.26)$ & $91.46(7.74)$ \\
\hline \multirow{3}{*}{ Chlorothalonil } & 0 & nd & nd & nd \\
\hline & 0.25 & 95.94 (8.79) & $83.04(3.38)$ & 83.85 (9.73) \\
\hline & 5 & $110.08(5.58)$ & $95.73(10.47)$ & $98.65(10.68)$ \\
\hline \multirow{3}{*}{ Ametryn } & 0 & $\mathrm{~d}(1.45 \mu \mathrm{g} / \mathrm{L})$ & $\mathrm{d}(4.80 \mu \mathrm{g} / \mathrm{L})$ & $\mathrm{d}(7.06 \mu \mathrm{g} / \mathrm{L})$ \\
\hline & 0.25 & 80.63 (7.97) & $86.52(4.87)$ & $82.00(6.68)$ \\
\hline & 5 & $85.53(5.55)$ & $98.36(3.75)$ & 80.39 (4.59) \\
\hline \multirow{3}{*}{ Malathion } & 0 & nd & nd & nd \\
\hline & 0.25 & $97.43(0.96)$ & $84.46(7.67)$ & $81.71(1.95)$ \\
\hline & 5 & $108.34(2.46)$ & 90.05 (7.18) & $111.52(3.26)$ \\
\hline \multirow{3}{*}{ Chlorpyrifos } & 0 & nd & nd & nd \\
\hline & 0.25 & $99.98(1.55)$ & $103(6.10)$ & $90.57(5.31)$ \\
\hline & 5 & $110.33(2.20)$ & $82.59(1.52)$ & $81.67(0.70)$ \\
\hline \multirow{3}{*}{ Dimethametryn } & 0 & nd & nd & nd \\
\hline & 0.25 & $94.97(9.48)$ & $80.48(2.42)$ & $84.20(10.70)$ \\
\hline & 5 & $112.46(4.75)$ & $85.99(5.41)$ & $100.71(7.45)$ \\
\hline
\end{tabular}

nd: not detected; d: detected. 
atrazine at $3 \mu \mathrm{g} / \mathrm{L}$ in water for human consumption. Similarly, the European Union (EU) set the maximum residue levels for individual pesticide at $0.1 \mu \mathrm{g} / \mathrm{L}$ and $0.5 \mu \mathrm{g} / \mathrm{L}$ for mixtures of pesticides [3]. Furthermore, EU has set the maximum residue levels (MRL) of $14 \mu \mathrm{g} / \mathrm{L}$ in the surface water and $250 \mu \mathrm{g} / \mathrm{L}$ in sugarcane juice for ametryn [47]. Based on the findings of this study, atrazine was detected only in the water sample of Wonji Shoa sugarcane irrigation, and the residue level determined, $4.12 \mu \mathrm{g} / \mathrm{L}$, which is higher than the limit set by EPA, even if the water from this source is not used for drinking purposes. On the other hand, the amounts of ametryn found in both water samples were below the MRL set by the EU for surface water. Similarly, the quantity of ametryn detected in the sugarcane juice was also below the MRL recommended by the EU. However, the findings of this study could be used as a warning alarm for the need of continuous monitoring program in order to protect the environmental deterioration, and minimizing human and animal health risks possibly caused by future accumulation of the pesticide residues in the study areas. Typical GC-MS chromatograms for the spiked and non-spiked Wonji Shoa sugar factory irrigation water samples are shown in Figure 8.

\subsubsection{Comparison of the Proposed Method with Similar Literature Reports}

The figures of merit of the HD-DLLME method developed in the presented study for determination of seven pesticides in water and sugarcane juice samples have been compared with other recently reported techniques including DLLME-GC-MS [1] [48], ion-pair assisted liquid-liquid extraction combined with high performance liquid chromatography diode array detection (IPA-LLE-HPLC-DAD) [49], dispersive micro-solid phase extraction combined with high resolution mass spectrometry (DMSPE-HRMS) [3] and dispersive liquid-liquid microextraction based on solidification of floating organic droplet (DLLME-SFO) [15]. Details of the relevant results of the methods and that of this study are provided in Table 3. Based on these findings, comparison was made and it was observed that the proposed method involves minimum labor and requires short extraction time. In addition, performances of the developed technique were compared with that of the previously reported techniques in terms of relative recovery, LOD and regression coefficient $\left(\mathrm{R}^{2}\right)$ and the findings confirmed that the developed technique are found to be comparable or better. Furthermore, it could also be noted that the developed method utilizes simpler and classical laboratory equipment and uses microliter amount of organic solvents, which could be accessible in most common research laboratories.

\section{Conclusions}

This study has focused on the potential applications of one of the miniaturized analytical techniques, i.e., a high density solvent based DLLME, utilized for selective and quantitative extraction of trace quantities of multiclass pesticide residues from different environmental samples. During method development, 
various parameters affecting the chromatographic separation and extraction efficiencies of the target analytes were evaluated and the optimum conditions were established. Under these conditions, the method was found to be linear over wide concentration ranges with coefficient of determination of 0.991 or better; LOD varied in the range of $0.005-0.02 \mu \mathrm{g} / \mathrm{L}$ and exhibited acceptable precision $(\% \mathrm{RSD} \leq 8.74)$ and satisfactory relative recoveries ranging from $80.39 \%-114.05 \%$. Employing the optimized experimental parameters, trace level extraction followed

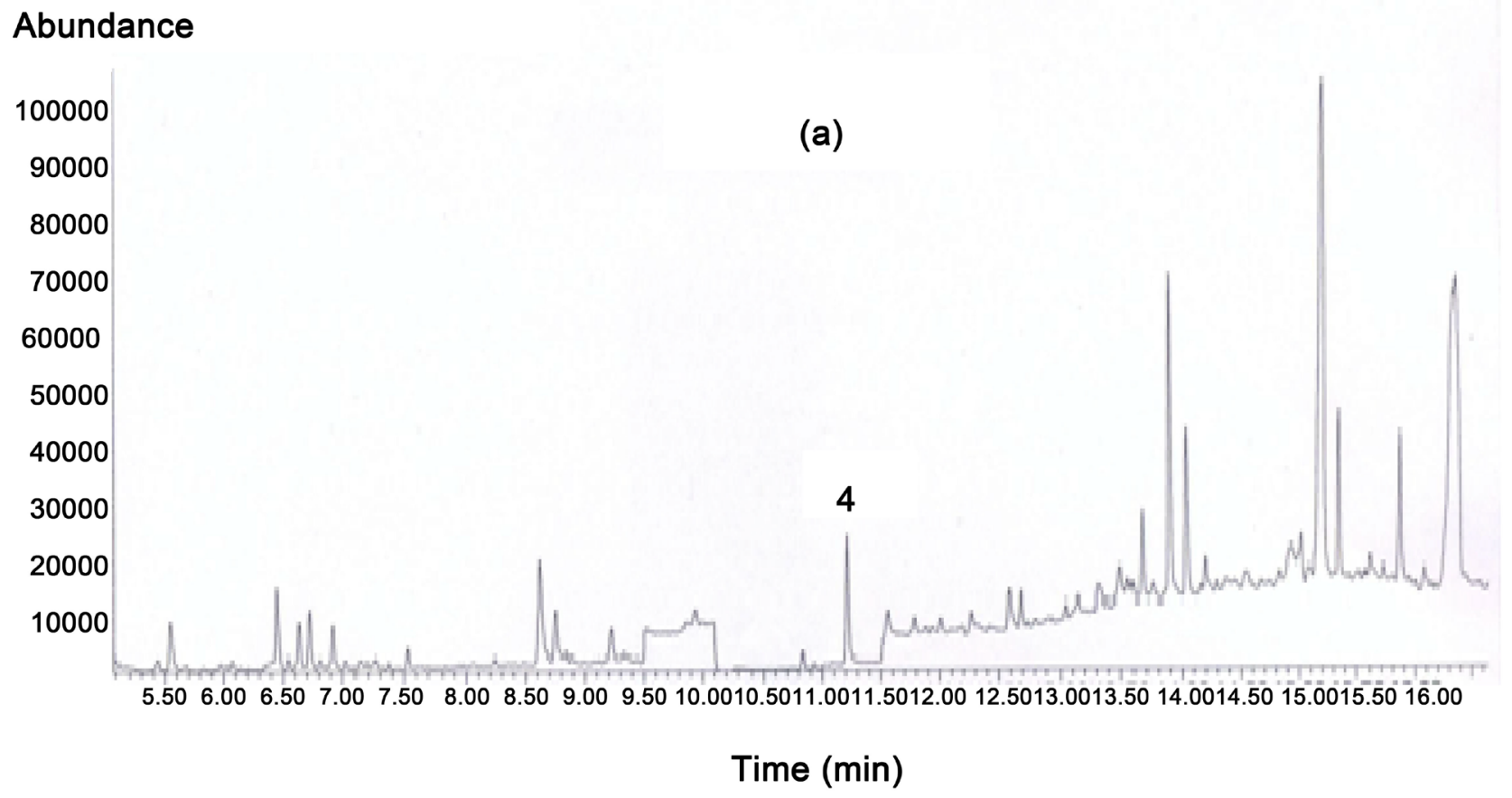

Abundance

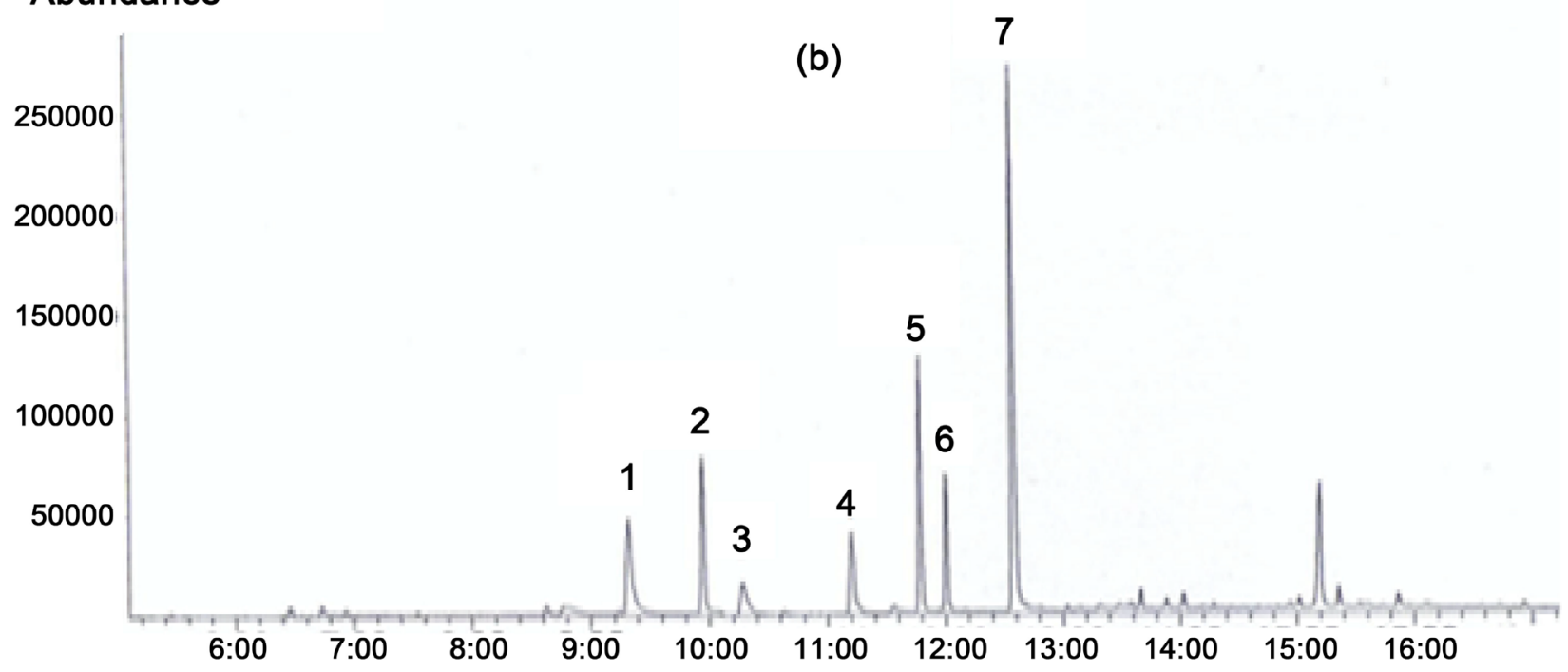

Time (min) 

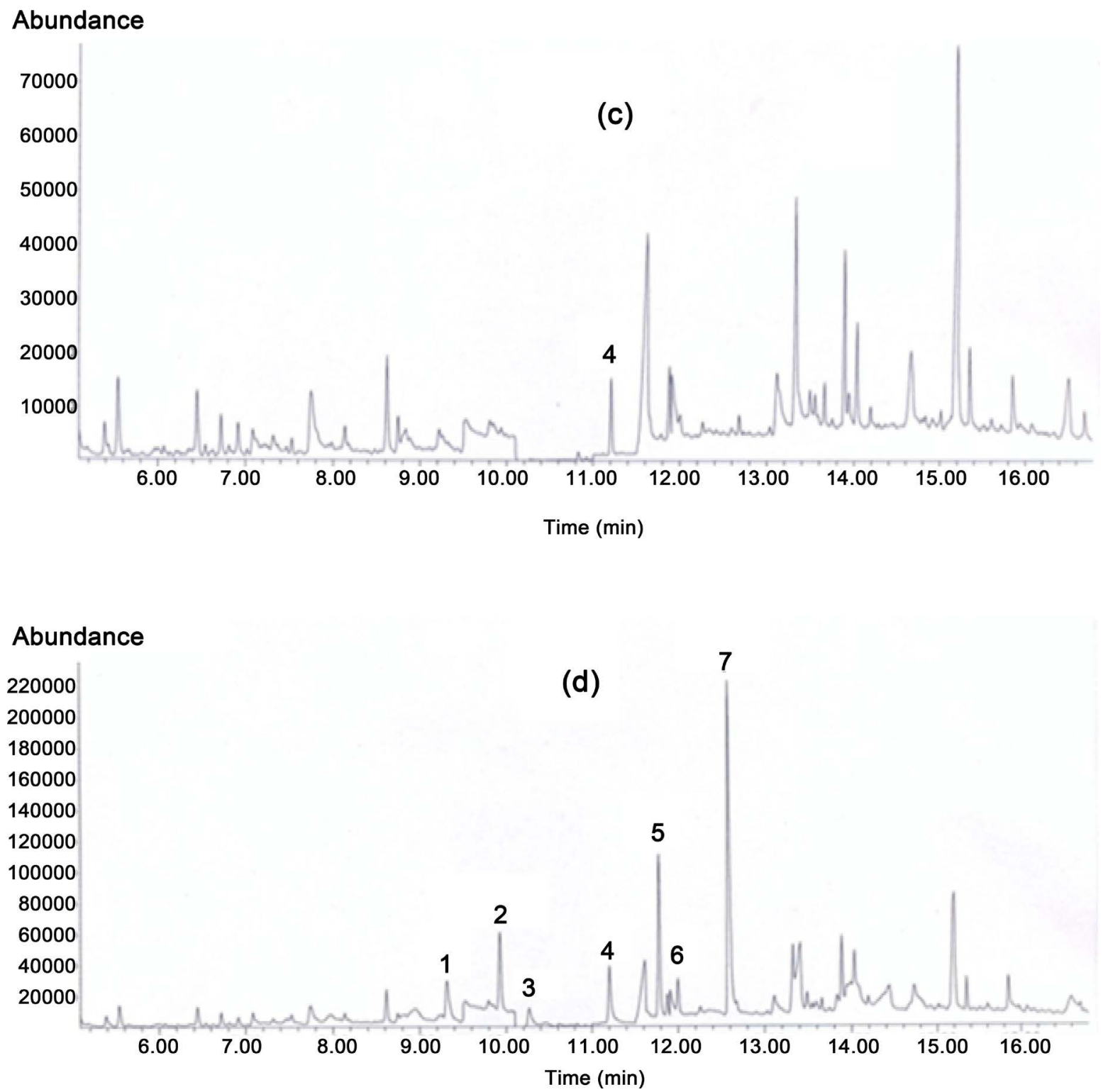

Figure 8. Representative chromatograms for blank (a) and spiked (b) Wonji Shoa sugarcane irrigation water; blank (c) and spiked (d) sugarcane juice; Peaks: 1, Atrazine; 2, diazinon; 3, chlorothalonil; 4, ametryn; 5, malathion; 6, chlorpyrifos; 7, dimethametryn.

Table 3. Comparison of the proposed HD-DLLME method with various modes of extraction methods.

\begin{tabular}{ccccccc}
\hline \multirow{2}{*}{ Methods } & Analyte & $\begin{array}{c}\text { Extraction } \\
\text { time }(\min )\end{array}$ & Recovery & LOD $(\mu \mathrm{g} / \mathrm{L})$ & $\mathrm{R}^{2}$ & $\mathrm{Ref}$ \\
DLLME-GC-MS & Chlorothalonil and chlorpyrifos & 2 & $75-113$ & $0.002-0.5$ & $0.998-0.999$ & {$[48]$} \\
IPA-LLE-HPLC-DAD & Chlorpyrifos, diazinon, fenitrothion and others & 20 & $73-105$ & $0.5-3.0$ & $0.993-0.997$ & {$[49]$} \\
DLLME-GC-MS & $\begin{array}{c}\text { Ametryn, desmetryn, dimethametryn, diprometryn, } \\
\text { metoprotryn, prometryn and terbumetryn }\end{array}$ & - & $85.2-114.5$ & $0.021-0.12$ & $0.978-0.9998$ & {$[1]$} \\
DMSPE-HRMS & Ametryn and atrazine dimethametryn & 1.5 & $71.1-91.5$ & $0.0003-0.006$ & $0.9993-0.9999$ & {$[3]$} \\
DLLME-SFO & Diethofencarb and pyrimethanil & 5 & $86.2-104.6$ & 0.24 and 0.09 & $0.9995-0.9996$ & {$[3]$} \\
HD-DLLME-GC-MS & Atrazine, diazinon, chlorothalonil, ametryn, malathion, \\
chlorpyrifos and dimethametryn & 3 & $80.4-114.0$ & $0.005-0.02$ & $0.992-0.999$ & $\begin{array}{c}\text { This } \\
\text { study }\end{array}$ \\
\hline
\end{tabular}


by GC-MS determination of the target analytes in the water samples collected from Hawassa Lake and Wonji Shoa sugarcane irrigation as well as sugarcane juice samples were successfully achieved. The results indicated that ametryn was detected in water from Hawassa Lake and sugarcane juice samples at concentration level of 1.45 and $4.12 \mu \mathrm{g} / \mathrm{L}$, respectively. Furthermore, atrazine and ametryn were detected in Wonji Shoa sugarcane irrigation water at concentration levels of $4.80 \mu \mathrm{g} / \mathrm{L}$ and $7.06 \mu \mathrm{g} / \mathrm{L}$, respectively.

Based on the experimental findings and the inference from the comparison, it can be generalized that the currently developed method is simpler, cheap, rapid and reliable for selective and quantitative extraction of trace level multiclass pesticide residues and other chemical pollutants, possessing similar physicochemical properties from contaminated samples of different origins.

\section{Acknowledgements}

The authors appreciate the continuing assistance of the Department of Chemistry of the Addis Ababa University (AAU), for the laboratory facilities and consumables provided. Expenses required for the field works and pesticide standards were obtained from International Science Program (ISP), through ETH:04 project. Teshome Tolcha is grateful to the Axum University for sponsoring his doctoral studies at the AAU.

\section{References}

[1] Nagaraju, D. and Huang, S. (2007) Determination of Triazine Herbicides in Aqueous Samples by Dispersive Liquid-Liquid Microextraction with Gas Chromatography-Ion Trap Mass Spectrometry. Journal of Chromatography A, 116, 89-97. https://doi.org/10.1016/j.chroma.2007.05.065

[2] Velkoska-Markovska, L. and Petanovska-Ilievska, B. (2013) Optimization and Development of a SPE-HPLC-DAD Method for the Determination of Atrazine, Malathion, Fenitrothion and Parathion Pesticide Residues in Apple Juice. Macedonian Journal of Chemistry and Chemical Engineering, 32, 299-308.

[3] Chen, D., Zhang, Y., Miao, H., Zhao, Y. and Wu, Y. (2015) Determination of Triazine Herbicides in Drinking Water by Dispersive Micro Solid Phase Extraction with Ultrahigh-Performance Liquid Chromatography-High-Resolution Mass Spectrometric Detection. Journal of Agricultural and Food Chemistry, 63, 9855-9862. https://doi.org/10.1021/acs.jafc.5b03973

[4] Liu, X., Xu, J., Dong, F., Li, Y., Song, W. and Zheng, Y. (2011) Residue Analysis of Four Diacylhydrazine Insecticides in Fruits and Vegetables by Quick, Easy, Cheap, Effective, Rugged, and Safe (QuEChERS) Method Using Ultra-Performance Liquid Chromatography Coupled to Tandem Mass Spectrometry. Analytical and Bioanalalytical Chemistry, 401, 1051-1058. https://doi.org/10.1007/s00216-011-5148-3

[5] Abu-qare, A.W. and Abou-donia, M.B. (2001) Determination of Diazinon, Chlorpyrifos and Their Metabolites in Rat Plasma and Urine by High-Performance Liquid Chromatography. Journal of Chromatographic Science, 39, 200-204. https://doi.org/10.1093/chromsci/39.5.200

[6] Cortada, C., Vidal, L., Pastor, R., Santiago, N. and Canals, A. (2009) Determination of Organochlorine Pesticides in Water Samples by Dispersive Liquid-Liquid Mi- 
croextraction Coupled to Gas Chromatography-Mass Spectrometry. Analytica Chimica Acta, 649, 218-221. https://doi.org/10.1016/j.aca.2009.07.041

[7] Díaz-Cruz, M.S. and Barceló, D. (2006) Highly Selective Sample Preparation and Gas Chromatographic-Mass Spectrometric Analysis of Chlorpyrifos, Diazinon and Their Major Metabolites in Sludge and Sludge-Fertilized Agricultural Soils. Journal of Chromatography A, 1132, 21-27. https://doi.org/10.1016/j.chroma.2006.07.062

[8] Fatoki, O.S. and Awofolu, R.O. (2003) Methods for Selective Determination of Persistent Organochlorine Pesticide Residues in Water and Sediments by Capillary Gas Chromatography and Electron-Capture Detection. Journal of Chromatography A, 983, 225-236. https://doi.org/10.1016/S0021-9673(02)01730-2

[9] Merdassa, Y., Liu, J.-F., Megersa, N. and Tessema, M. (2015) An Efficient and Fast Microwave-Assisted Extraction Method Developed for the Simultaneous Determination of 18 Organochlorine Pesticides in Sediment. International Journal of Environmental Analytical Chemistry, 95, 225-239.

https://doi.org/10.1080/03067319.2014.1002493

[10] Jorge, J.L.R. and Nilva, R. (2007) Determination of Organochlorine Pesticides in Ground Water Samples using Solid-Phase Microextraction by Gas Chromatography-Electron Capture Detection. Talanta, 72, 1833-1841. https://doi.org/10.1016/j.talanta.2007.02.024

[11] Peruga, A., Barreda, M., Beltrán, J. and Hernández, F. (2013) A Robust GC-MS/MS Method for the Determination of Chlorothalonil in Fruits and Vegetables. Food Additives and Contamination Part A, 30, 298-307. https://doi.org/10.1080/19440049.2012.738369

[12] Tolcha, T., Merdassa, Y. and Megersa, N. (2013) Low-Density Extraction Solvent Based Solvent-Terminated Dispersive Liquid-Liquid Microextraction for Quantitative Determination of Ionizable Pesticides in Environmental Waters. Journal of Separation Science, 36, 1119-1127. https://doi.org/10.1002/jssc.201200849

[13] Anyusheva, M., Lamers, M., Schwadorf, K. and Streck, T. (2012) Analysis of Pesticides in Surface Water in Remote Areas in Vietnam: Coping with Matrix Effects and Test of Long-Term Storage Stability. International Journal of Environmental Analytical Chemistry, 92, 97-809. https://doi.org/10.1080/03067319.2010.532872

[14] Lee, K.T., Tanabe, S. and Koh, C.H. (2001) Distribution of Organochlorine Pesticides in Sediments from Kyeonggi Bay and Nearby Areas. Environmental Pollution, 114, 207-213. https://doi.org/10.1016/S0269-7491(00)00217-7

[15] Cheng, J., Xiao, J., Zhou, Y., Xia, Y., Guo, F. and Li, J. (2011) Dispersive Liquid-Liquid Microextraction Based on Solidification of Floating Organic Droplet Method for the Determination of Diethofencarb and Pyrimethanil in Aqueous Samples. Microchimica Acta, 172, 51-55.

https://doi.org/10.1007/s00604-010-0458-2

[16] Saraji, M. and Boroujeni, M.K. (2014) Recent Developments in Dispersive Liquid-Liquid Microextraction. Analytical and Bioanalytical Chemistry, 406, 2027-2066. https://doi.org/10.1007/s00216-013-7467-Z

[17] Tobiszewski, M., Mechlińska, A., Zygmunt, B. and Namieśnik, J. (2009) Green Analytical Chemistry in Sample Preparation for Determination of Trace Organic Pollutants. Trends in Analytical Chemistry, 28, 943-951. https://doi.org/10.1016/j.trac.2009.06.001

[18] Yang, Z., Liu, Y., Liu, D. and Zhou, Z. (2012) Determination of Organophosphorus Pesticides in Soil by Dispersive Liquid-Liquid Microextraction and Gas Chromatography. Journal of Chromatographic Sciences, 50, 15-20. 
https://doi.org/10.1093/chromsci/bmr011

[19] Megersa, N. and Kassahun, S. (2012) A New Selective Liquid Membrane Extraction Method for the Determination of Basic Herbicides in Agro-Processed Fruit Juices and Ethiopian Honey Wine (Tej) Samples. Food Additives Contamination Part A, 29, 789-798. https://doi.org/10.1080/19440049.2011.653792

[20] Rezaee, M., Assadi, Y., Hosseini, M.M., Aghaee, E., Ahmadia, F. and Berijani, S. (2006) Determination of Organic Compounds in Water using Dispersive Liquid-Liquid Microextraction. Journal of Chromatography A, 1116, 1-9. https://doi.org/10.1016/j.chroma.2006.03.007

[21] Chen, H., Chen, R. and Li, S. (2010) Low-Density Extraction Solvent-Based Solvent Terminated Dispersive Liquid-Liquid Microextraction Combined with Gas Chromatography-Tandem Mass Spectrometry for the Determination of Carbamate Pesticides in Water Samples. Journal of Chromatography A, 1217, 1244-1248.

https://doi.org/10.1016/j.chroma.2009.12.062

[22] Farajzadeh, M.A., Seyedi, S.E., Shalamzari, M.S. and Bamorowat, M. (2009) Dispersive Liquid-Liquid Microextraction using Extraction Solvent Lighter than Water. Journal of Separation Science, 32, 3191-3200. https://doi.org/10.1002/jssc.200900109

[23] Zacharis, C.K., Tzanavaras, P.D., Roubos, K. and Dhima, K. (2010) Solvent-Based De-Emulsification Dispersive Liquid-Liquid Microextraction Combined with Gas Chromatography-Mass Spectrometry for Determination of Trace Organochlorine Pesticides in Environmental Water Samples. Journal of Chromatography A, 1217, 5896-5900. https://doi.org/10.1016/j.chroma.2010.07.065

[24] Ma J., Lu, W. and Chen, L. (2012) Recent Advances in Dispersive Liquid-Liquid Microextraction for Organic Compounds Analysis in Environmental Water. Current Analytical Chemistry, 8, 78-90. https://doi.org/10.2174/157341112798472170

[25] Viñas, P., Campillo, N., López-García, I. and Hernández-Córdoba, M. (2014) Dispersive Liquid-Liquid Microextraction in Food Analysis. Analytical and Bioanalytical Chemistry, 406, 2067-2099. https://doi.org/10.1007/s00216-013-7344-9

[26] Tsai, W. and Huang, S. (2009) Dispersive Liquid-Liquid Microextraction with Little Solvent Consumption Combined with Gas Chromatography-Mass Spectrometry for the Pretreatment of Organochlorine Pesticides in Aqueous Samples. Journal of Chromatography A, 1216, 5171-5175. https://doi.org/10.1016/j.chroma.2009.04.086

[27] Matsadiq, G., Hu, H., Ren. H., Zhou, Y., Liu, L. and Cheng, J. (2011) Quantification of Multi-Residue Levels in Peach Juices, Pulps and Peels using Dispersive Liquid-Liquid Microextraction Based on Floating Organic Droplet Coupled with Gas Chromatography-Electron Capture Detection. Journal of Chromatography B, 879, 2113-2118. https://doi.org/10.1016/j.jchromb.2011.05.047

[28] Lin, X., Chen, X., Huo, X., Yu, Z., Bi, K. and Li, Q. (2011) Dispersive Liquid-Liquid Microextraction Coupled with High-Performance Liquid Chromatography-Diode Array Detection for the Determination of N-Methyl Carbamate Pesticides in Vegetables. Journal of Separation Science, 34, 202-209.

https://doi.org/10.1002/jssc.201000590

[29] Saraji, M. and Tansazan, N. (2009) Application of Dispersive Liquid-Liquid Microextraction for the Determination of Phenylurea Herbicides in Water Samples by HPLC Diode Array Detection. Journal of Separation Science, 32, 4186-4192. https://doi.org/10.1002/jssc.200900438

[30] Megersa, N. and Jönsson, J.Å. (1998) Trace Enrichment and Sample Preparation of Alkylthio-s-Triazine Herbicides in Environmental Waters using a Supported Liquid 
Membrane Technique in Combination with High-Performance Liquid Chromatography. Analyst, 123, 225-231. https://doi.org/10.1039/a705361d

[31] Mnif, W., Hassine, A. I. H, Bouaziz, A., Bartegi, A., Thomas, O. and Roig, B. (2011) Effect of Endocrine Disruptor Pesticides. International Journal of Environmental Research and Public Health, 8, 2265-2303. https://doi.org/10.3390/ijerph8062265

[32] Farajzadeh, M.A., Goushjuii, L., Djozan, D. and Mohammadi, J.K. (2012) Dispersive Liquid-Liquid Microextraction Combined with Gas Chromatography for Extraction and Determination of Class 1 Residual Solvents in Pharmaceuticals. Journal of Separation Science, 35, 1027-1035. https://doi.org/10.1002/jssc.201100917

[33] Wang, Y., Miao, X., Wei, H., Liu, D., Xia, G. and Yang, X. (2016) Dispersive Liquid-Liquid Microextraction Combined with Gas Chromatography-Mass Spectrometry for the Determination of Multiple Pesticides in Celery. Food Analytical Methods, 9, 2133-2141. https://doi.org/10.1007/s12161-015-0390-5

[34] Liang, T., Lv, Z., Jiang, T. and Wang, Y. (2013) High-Density Extraction Solvent-Based Solvent De-Emulsification Dispersive Liquid-Liquid Microextraction Combined with MEKC for Detection of Chlorophenols in Water Samples. Electrophoresis, 34, 345-352. https://doi.org/10.1002/elps.201200355

[35] Hashemi, P., Hosseini, S.M. and Kakanejadifard, A. (2010) Dispersive Liquid-Liquid Microextraction of $\mathrm{Cu}(\mathrm{II})$ using a Novel Dioxime for Its Highly Sensitive Determination by Graphite Furnace Atomic Absorption Spectrometry. Journal of the Chinese Chemical Society, 57, 111-117. https://doi.org/10.1002/jccs.201000018

[36] Tabrizi, A.B. and Rezazadeh, A. (2012) Development of a Dispersive Liquid-Liquid Microextraction Technique for the Extraction and Spectrofluorimetric Determination of Fluoxetine in Pharmaceutical Formulations and Human Urine. Advanced Pharmaceutical Bulletin, 2, 157-164.

[37] Chang, C., Wei, S. and Huang, S. (2011) Improved Solvent Collection System for a Dispersive Liquid-Liquid Microextraction of Organochlorine Pesticides from Water using Low-Density Organic Solvent. Journal of Separation Science, 34, 837-843. https://doi.org/10.1002/jssc.201000728

[38] Li, Y., Zhang, W., Wang, R.G., Wang, P.L. and Su, X.O. (2015) Development of an Efficient and Sensitive Dispersive Liquid-Liquid Microextraction Technique for Extraction and Preconcentration of $10 \beta_{2}$-Agonists in Animal Urine. PLOS ONE, 10, e0137194.

[39] Xi, X., Yang, M., Shen, G., Wu, X., Lu, R., Zhou, W., Zhang, S. and Gao, H. (2016) Pipette Vial Dispersive Liquid-Liquid Microextraction Combined with High-Performance Liquid Chromatography for the Determination of Benzoylurea Insecticide in Fruit Juice. Journal of Separation Science, 39, 391-398.

https://doi.org/10.1002/jssc.201500714

[40] He, L., Luo, X., Jiang, X. and Qu, L. (2010) A New 1, 3-Dibutylimidazolium Hexafluorophosphate Ionic Liquid-Based Dispersive Liquid-Liquid Microextraction to Determine Organophosphorus Pesticides in Water and Fruit Samples by High-Performance Liquid Chromatography. Journal of Chromatography A, 1217, 5013-5020. https://doi.org/10.1016/j.chroma.2010.05.057

[41] Zhou, Q., Pang, L., Xie, G., Xiao, J. and Bai, H. (2009) Determination of Atrazine and Simazine in Environmental Water Samples by Dispersive Liquid-Liquid Microextraction with High Performance Liquid Chromatography. Analytical Science, 25, 73-76. https://doi.org/10.2116/analsci.25.73

[42] Bedassa, T., Gure, A. and Megersa, N. (2015) Low Density Solvent Based Dispersive Liquid-Liquid Microextraction and Preconcentration of Multiresidue Pesticides in 
Environmental Waters for Liquid Chromatographic Analysis. Journal of Analytical Chemistry, 70, 1199-1206. https://doi.org/10.1134/S1061934815100184

[43] Tadesse, B., Teju, E., Gure, A. and Megersa, N. (2015) Ionic Liquid Based Dispersive Liquid-Liquid Microextraction Combined with High-Performance Liquid Chromatography for the Determination of Multiclass Pesticide Residues in Water Samples. Journal of Separation Science, 38, 829-835. https://doi.org/10.1002/jssc.201401105

[44] Gure, A., Lara, F.J., García-campaña, A.M., Megersa, N. and Olmo-iruela, M. (2015) Vortex-Assisted Ionic Liquid Dispersive Liquid-Liquid Microextraction for the Determination of Sulfonylurea Herbicides in Wine Samples by Capillary High-Performance Liquid Chromatography. Food Chemistry, 170, 348-353. https://doi.org/10.1016/j.foodchem.2014.08.065

[45] Khalilian, F. and Rezaee, M. (2017) Ultrasound-Assisted Extraction Followed by Solid-Phase Extraction Followed by Dispersive Liquid-Liquid Microextraction for the Sensitive Determination of Diazinon and Chlorpyrifos in Rice. Food Analytical Methods, 10, 885-891. https://doi.org/10.1007/s12161-016-0653-9

[46] European Commission (2015) Guidance Document on Analytical Quality Control and Method Validation Procedures for Pesticides Residues Analysis in Food and Feed. SANTE/11945/2015.

[47] US EPA (2015) Standard Operating Procedure for Using PRZM-GW to Estimate Pesticide Concentrations in Groundwater for Drinking Water Exposure Assessments. Archive Document.

[48] Rocha, C., Pappas, E.A. and Huang, C.H. (2008) Determination of Trace Triazine and Chloroacetamide Herbicides in Tile-Fed Drainage Ditch Water using Solid-Phase Microextraction Coupled with GC-MS. Environmental Pollution, 152, 239-244. https://doi.org/10.1016/j.envpol.2007.04.029

[49] Gure, A., Megersa, N. and Retta, N. (2014) Ion-Pair Assisted Liquid-Liquid Extraction for Selective Separation and Analysis of Multiclass Pesticide Residues in Environmental Waters. Analytical Methods, 6, 4633-4642. https://doi.org/10.1039/C4AY00285G 